\title{
Adolescent Pregnancy among Ethnic Variants at Lumbini Medical College
}

\author{
Subha Shrestha, ,ac Buddhi Kumar Shrestha ${ }^{\mathrm{b}, \mathrm{c}}$
}

\begin{abstract}
:
Introduction: Adolescent pregnancy is a common social phenomenon that results to both maternal and fetal related health consequences globally. Important factors affecting this high risk group of pregnancies are social, cultural, ethnic and racial disparities which may limit the care during pregnancy thereby affecting the perinatal outcome. The main objective of this study was to estimate the maternal and fetal outcome of adolescent pregnancies visiting Lumbini Medical college among ethnic variants of mid-western region. Methods: A retrospective observational study was conducted in Lumbini Medical College and Teaching Hospital for one year duration. Data was retrieved from the medical records of the admitted adolescent pregnant mothers with hospital delivery after 20 weeks' gestation. Variables of interest were the selective demographic characteristics like place of residence and ethnicity of women, parity, and obstetrical \&fetal outcomes. Results: The total numbers of admission for deliveries during the study period were 1905, out of which 462 (24.3\%) were adolescent pregnancy. A total of 184 (39\%) adolescent mothers were at the age of 19 and 334 (72.2\%) of them were from Palpa district. The highest number of teenagers were from Janajati group i.e. 240 (52\%). Among all, $38(10 \%)$ had preterm delivery and $7(1.5 \%)$ had intrauterine fetal death. While 407 (88.3\%) adolescent pregnancies had vaginal deliveries, 54 (11.7\%)of them had lower segment cesarean section (LSCS). Fifty-one (11.4\%) neonates had low birth weight (below 2500 gm)and 11 (2.4\%) had stillbirths. Among the low birth weight, 32 (51\%) newborns were admitted to neonatal intensive care unit (NICU). Conclusions: Adolescent pregnancy is higher common in Palpa district of Nepal. Janajati adolescent girls are becoming pregnant early after marriage. Higher numbers of teenagers are 19 years of age and are primigravida. On reaching the tertiary center, obstetrical outcome is better with less maternal morbidity and no mortality and better neonatal survival.
\end{abstract}

Keywords: adolescent • ethnic groups • outcome • pregnancy

\section{INTRODUCTION:}

The period between the ages of 10 and 19 years in which the individual progresses from the initial appearances of secondary sexual characteristics to full sexual maturity; and during which psychological and emotional processes develop from those of a child to an adult, is

\footnotetext{
a - Lecturer,

b - Assistant Professor

c - Department of Obstetric and Gynecology

Lumbini Medical College, Palpa, Nepal
}

Corresponding Author:

Dr. Subha Shrestha

e-mail: subha_sht@hotmail.com

How to cite this article:

Shrestha S, Shrestha BK. Adolescent pregnancy among ethnic variants at Lumbini Medical College. Journal of Lumbini Medical College, 2015;3(1):1-4. doi: 10.22502/jlmc.v3i1.59. adolescence. ${ }^{1}$ Adolescent pregnancy is defined as gestation in teenagers before somatic development is reached. For millions of young people around the world, the onset of adolescence brings not only changes to their bodies but also new vulnerabilities to human rights abuses, particularly in the arenas of sexuality, marriage, and childbearing. ${ }^{2}$

About 16 million girls aged 15 to 19 and some one million girls below 15 give birth every year, most in low and middle socio-economic countries like Nepal. Complications during pregnancy and childbirth are the second cause of death for 15-19 years old girls globally. Babies born to adolescent mothers face a substantially higher risk of dying than those born to women aged 20 to $24 .^{3}$

To face the events of childbearing in a very young age is considered to be high risk because of the additional impact of reproduction on a body which is 
still to grow. ${ }^{4}$ Other important factors affecting this high risk group of pregnancies are social, cultural, ethnic and racial disparities which may limit the care during pregnancy thereby affecting the outcome of these adolescent pregnancies. Since limited studies has been done to address this particular issue on maternal and child health in our nation, this study was intended to assess the maternal and fetal outcome of adolescent pregnancy visiting Lumbini Medical college among ethnic variants of mid-western region

\section{METHODS:}

This was a retrospective observational study conducted at Department of Obstetrics and Gynecology of Lumbini Medical College Teaching hospital (LMCTH), Palpa from January 2015 to March 2015. During this period, records of last one year i.e. January 2014 to December 2014 were reviewed.

Records of all the adolescent pregnant girls were studied. The adolescent teenagers, 19 years or below, with period of gestation more than 20 weeks, who were admitted for safe confinement or delivery at LMCTH were enrolled in the study. Data was retrieved from the case sheets from medical records department of the hospital. Data regarding age, place of residence, ethnic groups as per the most populous ethnicity from Demographic survey of Nepal 2011 were studied. Perinatal outcome in terms of pregnancy complications, mode of delivery and maternal and neonatal morbidity and mortality was also noted.

Data was analyzed using SPSS version 16. Frequency and percent were calculated for categorical data while mean and standard deviation were found for continuous data.

\section{RESULTS:}

The total number of admissions during the study period were 1905, out of which 462 (24.3\%) were adolescent pregnancy. Most pregnancies 184 (39\%) were accounted among teenagers of 19 yrs which was followed by 18 yrs i.e. 161 (34\%). Pregnancy below 15 years of age was not encountered (Table 1).

Our study showed that adolescent teenagers' delivery was recorded maximum i.e. 334 (72.3\%) from respondents of Palpa district, where the hospital is situated. The highest number of teenagers were from Janajati i.e. 240 (52\%) while lowest were from Madhesi i.e one. Among all of the ethnic groups, most of the respondents were primigravida i.e 428(92.6\%).Third gravidity in adolescence were seen in Dalit only (Table 2). Complications during pregnancy and delivery outcome among adolescent mothers are shown in Table 3.

Among the admissions, one had molar pregnancy and belonged to the Janajati group, three had twin deliveries (one from dalit and two from Brahmin/Chhetri group) and 10 (2.1\%) had breech deliveries (five from Janajati, three from Brahmin Chhetri and one from Dalit group). During postpartum period, seven (1.5\%) had primary postpartum

Table 1: Distribution of adolescent pregnancy according to age

\begin{tabular}{ccc}
\hline Age of Teenager (years) & $\boldsymbol{n}$ & (\%) \\
\hline 15 & 6 & 1.3 \\
16 & 24 & 5.2 \\
17 & 87 & 18.8 \\
18 & 161 & 34.8 \\
19 & 184 & 39.8 \\
Total & $\mathbf{4 6 2}$ & $\mathbf{1 0 0}$ \\
\hline
\end{tabular}

Table 2. Distribution of ethnical variants according to gravidity

\begin{tabular}{lcccc}
\hline Ethnic variants & $\begin{array}{c}\text { Primi- } \\
\text { gravida }\end{array}$ & $\begin{array}{c}\text { Second } \\
\text { gravida }\end{array}$ & $\begin{array}{c}\text { Third } \\
\text { gravida }\end{array}$ & Total \\
\hline $\begin{array}{l}\text { Dalit } \\
n(\%)\end{array}$ & $\begin{array}{c}104 \\
(90 \%)\end{array}$ & $\begin{array}{c}9 \\
(7.8 \%)\end{array}$ & $\begin{array}{c}2 \\
(2.2 \%)\end{array}$ & $\begin{array}{c}115 \\
(25 \%)\end{array}$ \\
$\begin{array}{l}\text { Janajati } \\
n(\%)\end{array}$ & 223 & 17 & 0 & 240 \\
Chhetri/Brahmins & 96 & 6 & & $(52 \%)$ \\
$n(\%)$ & $(94.1 \%)$ & $(5.9 \%)$ & 0 & 102 \\
Muslims $n(\%)$ & 4 & 0 & 0 & 4 \\
Madhesi $n(\%)$ & 1 & 0 & 0 & 1 \\
\hline
\end{tabular}

Table 3: Pregnancy complications and maternal and fetal outcome among adolescent pregnancies

\begin{tabular}{lc}
\hline Variables & $\boldsymbol{n ( \% )}$ \\
\hline Pregnancy complications & \\
\hline Pregnancy induced hypertension & $3(0.6)$ \\
\hline Eclampsia & $2(0.4)$ \\
\hline Intrauterine fetal death & $7(1.5)$ \\
\hline Prelabour rupture of membranes & $6(1.2)$ \\
\hline Urinary tract infection & $4(0.8)$ \\
\hline Cholestasis of pregnancy & $1(0.2)$ \\
\hline Type of delivery & \\
\hline Vaginal & $408(88.3 \%)$ \\
\hline Caesarean section & $54(11.7 \%)$ \\
\hline
\end{tabular}


hemorrhage, seven (1.5\%) had retained placenta and two had puerperal sepsis and were managed accordingly.

The total numbers of live births were 446 (88.5\%) while stillbirths of 11 (2.4\%). Fifty-one (13.5\%) had low birth weight (below $2500 \mathrm{gm}$ ) neonates and 395 (88.5\%) had normal weight. Thirty-two (62 \%) newborns were admitted to neonatal intensive care unit (NICU) for prematurity and low birth weight.

\section{DISCUSSION:}

Although births among adolescents account for $11 \%$ of all births worldwide, they account for $23 \%$ of the overall burden of disease secondary to pregnancy and childbirth among women of all ages. In low and middle income countries, complications of pregnancy and childbirth are the leading cause of death in women aged 15-19 years. The vast majority of these births (95\%) occur in low and middleincome countries. Various countries have vast variation ranging from one to 299 births per 1000 girls, with the highest rates in sub-Saharan Africa. ${ }^{2}$

First pregnancy at an early age is risky. This is why the prevention of adolescent pregnancy is an effective intervention that contributes to Millennium Development Goal 5 (Improve maternal health). Deducting adolescent pregnancy is necessary for this goal which focuses on reducing childhood \&maternal mortality. Prioritization of adolescent pregnancy decrement policies is included in National reproductive health policies of many countries. ${ }^{5}$

Annual report of Nepal Department of health had mentioned the rate of $17 \%$ among adolescence girls, who are either pregnant or a mother of one child before 19 years of age. ${ }^{5-8}$ Our study showed $24.3 \%$ rate of adolescent pregnancy among teenagers visiting our hospital, which is higher in numbers compared to other studies. Within South East Asia, the recorded adolescent pregnancy is highest in Bangladesh 35\%, followed by Nepal $21 \%$ and India 21\%. Our study result is similar to the study conducted at by Sah RB. et al. in Nobel Medical College showing 34.6 \% of adolescence pregnancy, 39\% belonging to Brahmin /Chhetri group and 50.8\% in Janajati group. ${ }^{7}$

The incidence of preterm delivery was less $(10 \%)$ in our study as compared to studies of Tripathi M. et al, Prianka M. et al, and Khooshideh M. et al., whose studies result showed the rate of preterm delivery as $20 \%, 27 \%$, and $19 \%$ respectively. ${ }^{9-11}$
Another comparable results of preterm labor and delivery with our study is the findings by Thaker RV. et al. i.e. $17.8 \% .^{12}$

We calculated the lower rate of caesarean section, preterm delivery, intrauterine fetal deathand hypertensive disorders similar to the findings by Kayastha S. et al. and Pun KD. et al. Similar to Pun KD. et al, our study showed vaginal deliveries being the commonest route of delivery and perinatal complications were in higher order among adolescent girls with no maternal mortality during study period. ${ }^{13-14}$

The better predisposition of adolescent pregnant women to have a spontaneous vaginal delivery is due to better myometrial function, greater connective tissue elasticity and lower cervical compliance. $^{15}$

Our study revealed $1.5 \%$ intrauterine fetal death, $2.4 \%$ stillbirths, $11.4 \%$ low birth weight and $62 \%$ needing NICU service among the low birth weight. Better and timely availability of NICU facilities to resuscitate very low birth weight babies might have been the reason for positive results among admitted neonates Higher birth weight of spontaneous vaginal delivery has minimized the overall adverse perinatal outcome apart from prematurity.

Babies delivered by adolescent mother are likely to be premature, so the incidence of low birth weight ( $<2500$ grams) is higher in them. Low birth weight is an outcome of malnutrition which is an important determinant of childhood mortality. Our study revealed less number of low birth weight babies, so it seems maternal nutrition is better in adolescent mothers of Palpa district of Nepal in comparison to other remote areas of Nepal.

\section{CONCLUSIONS:}

Adolescent pregnancy is high in Palpa and nearby districts of mid-western region of Nepal with greater preponderance among the Janajati group. Adolescent pregnancy results in adverse maternal and fetal outcome, adding up perinatal morbidity and mortality. Overall obstetrical outcome of adolescent pregnancy at LMCTH is good with less maternal morbidity, no mortality and high neonatal survival rate. This study shows that we can have a better feto-maternal outcome with institutional deliveries. Preventive measures by the government like health education to women and men of all ethnic groups, 
awareness programs at school levels regarding age at marriage, contraceptive methods and risks of teenage pregnancy might reduce the incidence of adolescent pregnancies.

\section{REFERENCES:}

1. World Health Organization. Adolescent sexuality and reproductive health: Educational and service aspect. Report of World Health Organization meeting in Mexico City.1981 28th April- 2nd May.

2. World Health Organization. Adolescent pregnancy. Media center. Fact sheets. 2014 Sept-Nov.

3. WHO. Preventing early pregnancy and poor reproductive outcomes among adolescents in developing countries.2011;195

4. Bacci A, Manhica GM, Machungo F, Bugalho A, Cuttini M. Outcome of teenage pregnancy in Maputo, Mozambique. Int. J GynecolObstet. 1993:40(1);1923.

5. WHO. Early marriages, adolescent and young pregnancies.65th world health assembly.2012 mar; vol13(4).

6. The World Bank. Children and youth. The World Bank, Washington DC, 2004.

7. SahRB,, Kumar G, Baral DD, Jha N, Pokharel PK. Burden of Teenage pregnancies in hilly area of eastern region of Nepal. J Nobel Med Col. Vol3(1):13-9.

8. Department of Health Services (2011). Annual Report. Ministry of Health and Population, Government of Nepal. [Online]. Available from: http://dohs.gov.np/ sites/default/files/1/files/Annual_Report_2066_67.
Conflict of interest declared: None.

pdf (Accessed May 27, 2013).

9. Tripathi M, Sherchan A. Outcome of Teenage pregnancy. J Uni Col med sci. 2014;2(6):11-4.

10. Mukhopadhaya P, Chauduri RN, Paul B. Hospital based perinatal outcomes and complications in Teenage pregnancy in India. J Health Popul Nutr. 2010 Oct ;28(5):494-500.

11. Maryam K, Ali S. Pregnancy outcome in teenagers in East Sauterne of Iran. J Pak Med Assoc. 2008 Oct;58(10):541-44.

12. Thaker RV, Panchal MV, Vyas CS, Shah SR, Shah PT, Deliwala KJ. Study of feto-maternal outcome of teenage pregnancy at tertiary care hospital. Gujarat Med J .2013 Dec;68(2):100-3.

13. Kayastha S, Pradhan A. Obstetric outcome of Teenage Pregnancy. NJOG. 2012 Jul-Dec;17(2):29-32 .

14. Pun KD, Chauhan M. Outcome of adolescent pregnancy at Kathmandu university hospital, Dhulikhel, Kavre. Kathmandu Univ Med J. 2011 JanMar;9(33):50-3.

15. Jolly MC, Sebire N, Harris J, Robinsons S, Regan L. Obstetric risks of pregnancy in women less than 18 years old. Obstet Gynecol. 2000;96:962-6. 